\title{
DEVELOPMENT AND CHARACTERIZATION OF A COMPOSITE ANTHILL-CHICKEN EGGSHELL CATALYST FOR BIODIESEL PRODUCTION FROM WASTE FRYING OIL
}

\author{
Adeyinka S. Yusuff ${ }^{1,2 *}$, Olalekan D. Adeniyi², Moses A. Olutoye ${ }^{2}$, Uduak G. Akpan² \\ ${ }^{1}$ Department of Chemical and Petroleum Engineering, College of Engineering, Afe Babalola \\ University, Ado-Ekiti, Nigeria \\ ${ }^{2}$ Department of Chemical Engineering, School of Engineering and Engineering Technology, Federal \\ University of Technology, Minna, Nigeria
}

(Received: March 2017 / Revised: September 2017 / Accepted: January 2018)

\begin{abstract}
The primary aim of this research is to synthesis composite anthill-chicken eggshell catalyst, which is characterized and employed for the synthesis of biodiesel from waste frying oil. The as-synthesized catalyst was characterized using various characterization techniques, such as Xray fluorescence (XRF), Fourier transform infrared radiation (FTIR), Brunauer-Emmett-Teller (BET) analysis, scanning electron microscopy (SEM), and Basicity. The influence of different reaction parameters on the catalytic reaction, reaction time, catalyst loading and reaction temperature in the range of $50-75^{\circ} \mathrm{C}$ were studied at fixed methanol/oil ratio of $6: 1$. The experimental data obtained showed that at reaction time of $2 \mathrm{~h}$, catalyst loading of $5 \mathrm{wt} \%$ and reaction temperature of $60^{\circ} \mathrm{C}$, the biodiesel yield was $70 \%$. The synthesized catalyst was found to convert low-grade oil into biodiesel via a single-step transesterification process, and its activity has the potential for improvement.
\end{abstract}

Keywords: Anthill; Biodiesel; Chicken eggshell; Transesterification; Waste frying oil

\section{INTRODUCTION}

The application of solid-based catalysts in the field of renewable energy to produce renewable fuel has become a significant area of research due to environmental concerns resulting from the continual dependence on fossil fuel sources, current industrial energy demands and upswing in the world population. To this end, current research is focusing on fuel derivable from renewable sources using heterogeneous catalysts, which are utilized in the transportation industries and other industrial processes. The development of heterogeneous catalysts from waste and naturally occurring materials doped with metals for hydrocarbon (triglyceride) reactions is a specific area of interest that requires more research attention.

Further, there is an increasing interest in searching for naturally occurring minerals and domestic waste materials as heterogeneous catalysts due to their low cost and high availability. Most of these materials have been reported to be promising options in synthesizing biodiesel via heterogeneous transesterification (Wei et al., 2009). They provide a clean, almost glycerolfree biodiesel and reduce biodiesel production cost. Studies have shown that $\mathrm{CaO}$ derived from waste carbonaceous materials is a potential solid catalyst in biodiesel production process, and this has been done using chicken eggshell (Sharma et al., 2010), ostrich eggshell (Tan et al.,

\footnotetext{
*Corresponding author's email: : yusuffas@abuad.edu.ng, Tel: +234-708-656-5379, Fax: +234-708-656-5379 Permalink/DOI: https://doi.org/10.14716/ijtech.v9i1.1166
} 
2015), and waste animal bone (Obadiah et al., 2012). According to Henne (2009), an anthill is a form of fire clay which is made up of silica $\left(\mathrm{SiO}_{2}\right)$, alumina $\left(\mathrm{Al}_{2} \mathrm{O}_{3}\right)$, iron oxide $\left(\mathrm{Fe}_{3} \mathrm{O}_{4}\right)$ and many other metal oxides. Numerous researchers have used $\mathrm{SiO}_{2}$ and $\mathrm{Al}_{2} \mathrm{O}_{3}$ as catalyst supports in heterogeneous catalyzed transesterification. Furthermore, as reported by Olutoye and Hameed (2013), thermally treated clay has been used as heterogeneous catalyst for transesterification reaction. For instance, Olutoye et al. (2016) investigated transesterification of waste cooking oil with methanol using barium-modified montmorillonite clay as catalyst. The thermal treatment of these catalytic materials at an elevated temperature of $600^{\circ} \mathrm{C}$ up to $1000^{\circ} \mathrm{C}$ transforms the components into a new phase of highly active mixed metal oxide with strong interaction (Olutoye \& Hameed, 2013; Tan et al., 2015).

Recently, many studies have shown that the composite/supported catalyst could be derived from combination of different catalytic materials and use as a potential heterogeneous catalyst in the biodiesel production process (Lakhya et al., 2012). However, no previous researchers have used a combination of waste (biomass) and naturally occurring materials for the development of composite catalysts. Thus, the aim of this study is to synthesize a composite anthill-eggshell (CAE), which is employed as a highly active heterogeneous catalyst via the transesterification of waste frying oil (WFO) with methanol to produce biodiesel. The prepared catalyst is characterized to gain insight into its properties. The effects of various parameters, namely the reaction temperature, reaction period, and catalyst loading, which influence the process, are investigated. Moreover, the physicochemical and fuel properties of biodiesels produced under optimum reaction conditions are determined to ascertain their quality.

\section{METHODOLOGY}

\subsection{Material}

The harvested anthill employed was situated at the back of the works department of Afe Babalola University (ABUAD), Ado-Ekiti, Nigeria. The chicken eggshells and WFO were both collected from the students' cafeteria at ABUAD. The acid value, free fatty acid and saponification value of the WFO were $3.945 \mathrm{mgKOH} / \mathrm{g}, 1.973 \mathrm{wt} \%$ and $183.1 \mathrm{mgKOH} / \mathrm{g}$, respectively. The methanol used was synthesis-grade $(99.5 \%)$ and procured from Nizo Chemical Enterprise, Akure, Nigeria.

\subsection{Preparation of the Composite Anthill-Eggshell (CAE) Catalyst}

The harvested anthill was ground into powder and screened to obtain a particle size of 150-220 $\mu \mathrm{m}$. The resulting fine anthill powder was kept in an enclosed container. The waste chicken eggshells were first soaked for a day and thoroughly washed with tap water to remove impurities and the inner white membrane, followed by another washing with distilled water. Following this, the clean eggshells were dried in an oven at $120^{\circ} \mathrm{C}$ for $6 \mathrm{~h}$ to eliminate water. The dried eggshells were milled to obtain the fine powder and sieved to obtain a 150 - to $220-\mu \mathrm{m}$ particles size. The sieved chicken eggshell powder was kept in sealed plastic container. The CAE catalyst was synthesized based on the optimal preparation conditions obtained from our preliminary experiment. Typically, a 200-g of mixture of anthill and eggshell powders was formulated via incipient wetness impregnation (IWI) in 20-80\% proportions of anthill to eggshell on a mass basis. An appropriate amount of distilled water was added to the powders mixture and stirred for $90 \mathrm{~min}$ on a temperature-controlled magnetic stirrer for homogenization. The mixtures were then filtered and the residue was placed in an oven to remove excess water at a temperature of $125^{\circ} \mathrm{C}$ for $2 \mathrm{~h}$. The resulting dried powders mixture was calcined in the furnace at a temperature of $1,000^{\circ} \mathrm{C}$ for $4 \mathrm{~h}$. A heating rate of $10^{\circ} \mathrm{C} / \mathrm{min}$ was adopted. 


\subsection{Characterization of the As-synthesized Catalyst}

The basicity of the raw and calcined catalysts was determined via the colorimetric titration method. The textural properties of the catalysts were obtained via the BET and DubininRadushkevich (DR) methods using a Quantachrone instrument (Nova station-A model no. 11.03). The catalyst sample was degassed at $200^{\circ} \mathrm{C}$ for $5 \mathrm{~h}$ before taking the adsorption data. The functional groups contained in the catalyst samples were examined using a Fourier transform infrared (FTIR) analyzer model IR Affinity-1S (Shimadzu, Japan). X-ray fluorescence (XRF) analysis of the raw anthill and calcined CAE catalyst were carried out using a skyray simultaneous ED-XRF analyzer (model no. EOX3600B). Moreover, the external surface morphology of the catalysts was viewed using scanning electron microscopy (SEM; Phenom ProX MVE016477830 PhenomWorld).

\subsection{Transesterification Reaction Study}

The transesterification of WFO into biodiesel using the calcined CAE catalyst was carried out in a batch reactor made up of a $250-\mathrm{mL}$ one-way round bottomed flask fitted with a condenser and thermometer. The reaction was performed under different conditions, considering the catalyst loading (1-9 wt\%), reaction temperature $\left(50-75^{\circ} \mathrm{C}\right)$, and reaction time $(1-3 \mathrm{~h})$, while keeping the methanol/WFO molar ratio and stirring rate constant. After the completion of the reaction, the resulting mixture was filtered using a white cloth to remove the spent catalyst, and the filtrate was poured into a separating funnel and left overnight to settle. During the process, two layers of liquid were observed, in which the upper layer was biodiesel and the lower layer was indicated to be glycerol. Thus, the biodiesel yield was determined theoretically by Equation 1 as given by Leung et al. (2010):

$$
\text { Biodiesel yield }(\%)=\left[\frac{\text { Weight of biodiesel }}{\text { Weight of } \text { Wco fed }}\right] \times 100 \%
$$

The biodiesel prepared under the optimum reaction conditions was characterized by FTIR, and some of its physicochemical properties were determined according to the American Society for Testing and Materials (ASTM) standard methods.

\section{RESULTS AND DISCUSSION}

The research methodology used in the present study was implemented in the following stages.

\subsection{Catalyst Characterization}

\subsubsection{Basicity determination}

The basicity levels of the raw and calcined (CAE) catalysts were determined to be 2.05 and $10.80 \mathrm{mmol} / \mathrm{g}$ catalyst, respectively. The basicity result demonstrated that the basic strength of the calcined catalyst was higher than that of the raw catalyst. This confirmed the reason for the former to exhibit better activity than the later when they were both employed for transesterification reactions under the same reaction conditions. The strong basicity of calcined $\mathrm{CAE}$ is attributed to the complete decomposition of the calcium carbonate contained in the eggshell and organic matter in the anthill, which transformed into more active mixed metal oxides with close interaction. Moreover, as revealed by the XRF analysis (Table 2), the presence of a high content of calcium and other stearate metals was partly responsible for the basicity of the calcined CAE. This finding was confirmed by the study conducted by Di Serio et al. (2005) who demonstrated that a high fatty acid methyl esters (FAME) yield could be achieved in a relatively short reaction period when stearate metal oxides were tested as catalysts for the methanolysis of soybean oil. However, in their oxide forms, these active metals possess Lewis acidity (electron acceptor), and thus, their negative oxygen ions are Lewis bases (proton acceptor; Chorkendorff \& Niemantsverdriet, 2003). Therefore, the high basicity exhibited by 
thermally treated CAE implied that Lewis base sites are active centers for transesterification reactions.

\subsubsection{Textural properties analysis}

The physical properties of the as-synthesized catalyst samples, which included the surface area, total pore volume and average pore diameter, were determined. The surface areas of the catalysts were computed using the Brunauer-Emmett-Teller (BET) model, the analysis results are presented in Table 1.

Table 1 Physical properties of raw and calcined CAE catalysts

\begin{tabular}{lccc}
\hline Sample & BET Surface Area $\left(\mathrm{m}^{2} / \mathrm{g}\right)$ & Total Pore Volume $\left(\mathrm{cm}^{3} / \mathrm{g}\right)$ & Average Pore Diameter $(\AA)$ \\
\hline Raw & 3.80 & 0.00767 & 2.261 \\
Calcined & 74.56 & 0.02279 & 13.24 \\
\hline
\end{tabular}

The physical property analysis results presented in Table 1 showed that the calcined CAE had the highest BET surface area, at $74.56 \mathrm{~m}^{2} / \mathrm{g}$, and total pore volume at $0.02279 \mathrm{~cm}^{3} / \mathrm{g}$. In addition, the raw CAE possessed a BET surface area of $3.80 \mathrm{~m}^{2} / \mathrm{g}$ and total pore volume of $0.00767 \mathrm{~cm}^{3} / \mathrm{g}$. These values imply that the external surface of the calcined catalyst is dominated by the active ingredient (Tan et al., 2015) and can enhance the mass transfer of methanol onto the catalyst surface due to the expanded pore diameter. However, the pore diameters of both the raw and calcined CAE catalysts, which were found to be $2.261 \AA$ (or $2.261 \mathrm{~nm}$ ) and $13.24 \AA$ (or $13.24 \mathrm{~nm}$ ) respectively indicated that they are mesoporous materials, as both values fall in the range of $2-50 \mathrm{~nm}$ (Leofanti et al., 1997). Therefore, it can be concluded that the thermal treatment of CAE has positive and synergetic effects on its performance. This was corroborated by the basicity and SEM analyses.

\subsubsection{X-ray Fluorescence (XRF) analysis}

The chemical composition of the raw anthill and calcined CAE catalyst were analyzed using the $\mathrm{XRF}$ and ignition loss methods. The obtained results are presented in Table 2.

Table 2 Chemical composition analysis of raw anthill and synthesized CAE catalyst by XRF and loss on ignition (LOI) methods

\begin{tabular}{lcc}
\hline \multirow{2}{*}{ Compound } & \multicolumn{2}{c}{ Chemical Composition of Sample (wt\%) } \\
\cline { 2 - 3 } & Raw Anthill & CAE \\
\hline Aluminum oxide $\left(\mathrm{Al}_{2} \mathrm{O}_{3}\right)$ & 13.64 & 0.66 \\
Silicon oxide $\left(\mathrm{SiO}_{2}\right)$ & 58.46 & 1.80 \\
Phosphorus oxide $\left(\mathrm{P}_{2} \mathrm{O}_{5}\right)$ & 0.29 & 0.42 \\
Trioxosulphate $\left(\mathrm{SO}_{3}\right)$ & 0.38 & 0.47 \\
Potassium oxide $\left(\mathrm{K}_{2} \mathrm{O}\right)$ & 3.17 & - \\
Calcium oxide $(\mathrm{CaO})$ & 0.21 & 76.71 \\
Titanium oxide $\left(\mathrm{TiO}_{2}\right)$ & 0.38 & - \\
Iron $(\mathrm{III})$ oxide $\left(\mathrm{Fe}_{2} \mathrm{O}_{3}\right)$ & 6.47 & 0.84 \\
Molybdenum oxide $\left(\mathrm{MoO}_{2}\right)$ & 0.24 & 0.30 \\
Tin oxide $\left(\mathrm{SnO}_{2}\right)$ & 1.19 & 0.53 \\
Antimony oxide $\left(\mathrm{Sb}_{2} \mathrm{O}_{3}\right)$ & 1.21 & 0.49 \\
Nickel oxide $(\mathrm{NiO})$ & 0.059 & 0.034 \\
Copper oxide $(\mathrm{CuO})$ & 0.059 & 0.034 \\
Zinc oxide $(\mathrm{ZnO})$ & 0.11 & 0.061 \\
Manganese oxide $\left(\mathrm{MnO}_{2}\right)$ & 0.068 & 0.0039 \\
Tungsten oxide $\left(\mathrm{WO}_{3}\right)$ & 0.037 & 0.025 \\
LOI & 14.03 & 17.62 \\
\hline \multicolumn{1}{c}{ Total } & 100 & 100 \\
\hline
\end{tabular}


The findings revealed that the major constituents in the anthill were silica $\left(\mathrm{SiO}_{2}\right)$, alumina $\left(\mathrm{Al}_{2} \mathrm{O}_{3}\right)$ and ferric oxide $\left(\mathrm{Fe}_{2} \mathrm{O}_{3}\right)$, with approximate percentages of 58.46, 13.64 and $6.47 \%$, respectively, summing up to a total of $78.57 \%$. With respect to the silica $\left(\mathrm{SiO}_{2}\right)$ and alumina $\left(\mathrm{Al}_{2} \mathrm{O}_{3}\right)$ values, these results confirm the chemical analysis of clay (Olutoye \& Hameed, 2013) and follow the same trend of values reported by Henne (2009) for fire clay samples. The anthill sample was also found to contain rare earth metal oxides and transition elements; some of these are scarce and rarely found in normal clay samples, implying a good discovery. Rare metal oxides have been proven to be the most suitable solid catalyst in biodiesel production (Olutoye \& Hameed, 2013).

As illustrated in Table 2, the chemical composition of the calcined CAE catalyst showed that calcium oxide $(\mathrm{CaO})$ constituted a larger percentage. The high content of $\mathrm{CaO}$ was a result of the decomposition of $\mathrm{CaCO}_{3}$ contained in the chicken eggshell into $\mathrm{CaO}$ and $\mathrm{CO}_{2}$ at an elevated calcination temperature. This result agreed reasonably well with the findings reported by Eletta et al. (2016). In addition, the $\mathrm{SiO}_{2}$ detected in the CAE by the XRF machine confirmed the presence of anthill. Meanwhile, the high losses on ignition (LOIs) recorded in both the raw anthill and calcined CAE catalyst samples were a result of the adsorbed gases, organic matter, and moisture content (Tsai et al., 2006; Eletta et al., 2016). This was corroborated by the FTIR analysis carried out on the calcined CAE catalyst.

\subsubsection{Fourier Transform Infrared Radiation (FTIR) spectroscopy}

The FTIR characterization technique is used to identify the functional groups present in an unknown substance. Here, the FTIR analysis was carried out on both the raw and calcined CAE catalysts and compared. As shown in Figure 1, the major absorption peaks in the raw CAE appeared at $3425.69,1797.721421 .57,875.78$, and $713.69 \mathrm{~cm}^{-1}$. The broad absorption bands at approximately $3350-3500 \mathrm{~cm}^{-1}$ for the raw CAE were attributed to the $\mathrm{OH}$ stretching vibration from absorbed moisture. Moreover, the absorption bands at around 1425, 876 and $710 \mathrm{~cm}^{-1}$ for the raw CAE catalyst were assigned to the C-O asymmetric stretching, out-of-plane bending, and in-plane bending vibration modes of $\mathrm{CO}_{3}^{2-}$ from $\mathrm{CaCO}_{3}$ (Sharma et al., 2010). In addition, the appearance of a band around $1800 \mathrm{~cm}^{-1}$ could be attributed to the $\mathrm{C}=\mathrm{O}$ stretching of the aldehydes.

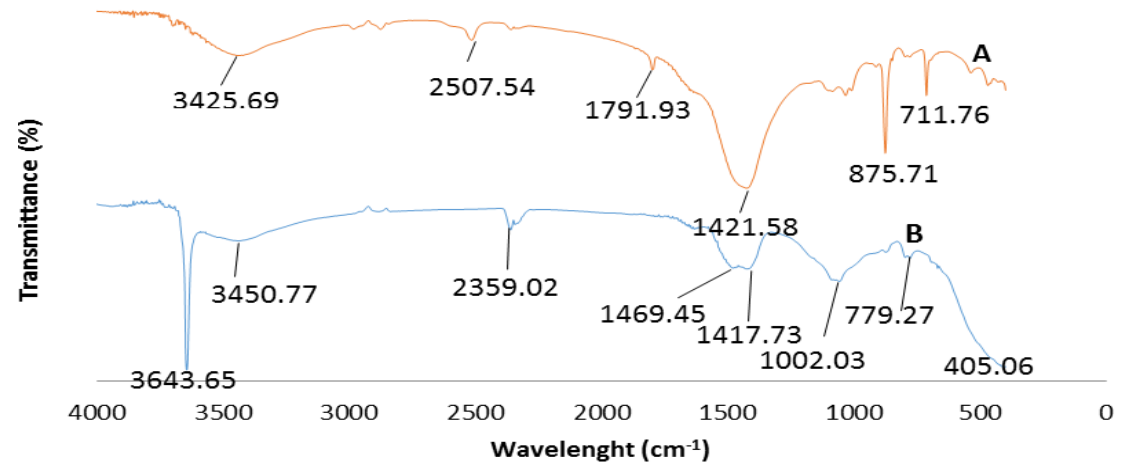

Figure 1 FTIR spectra of the (A) raw and (B) calcined CAE catalysts

After thermal treatment of $\mathrm{CAE}$ at $1,000^{\circ} \mathrm{C}$, the catalyst constituents transformed into a new phase of more active components, with functional groups that were different from those contained in the raw catalyst. As shown in Figure 1, the major absorption bands obtained for the calcined CAE were 3643.65, 3450.77, 2359.02, 1469.45, 1417.73, 1057.03, and $405.06 \mathrm{~cm}^{-1}$. Therefore, the presence of absorption peaks at $3700-3325 \mathrm{~cm}^{-1}$ could be assigned to the $\mathrm{OH}$ stretching from the $\mathrm{Ca}(\mathrm{OH})_{2}$ formed due to the hydroscopic nature of the derived CaO-based catalyst. A similar observation was reported by Roschat et al. (2012). The appearance of bands 
at 1469.45 and $1463.66 \mathrm{~cm}^{-1}$ are attributed to $\mathrm{CH}_{3}$ antisymmetric deformation and $\mathrm{CH}_{2}$ scissor vibration, respectively. In addition, the band at $1417.73 \mathrm{~cm}^{-1}$ corresponded to Vinyl $\mathrm{C}-\mathrm{H}$ inplane bend. The observed trough at approximately $1000-900 \mathrm{~cm}^{-1}$ was due to the presence of silicate ion or the $\mathrm{C}-\mathrm{H}$ out-of-plane bend of alkenes. Furthermore, the absorption bands at less than $500 \mathrm{~cm}^{-1}$ were due to $\mathrm{CaO}$ vibration (Tan et al., 2015). The good activity exhibited by the CAE catalyst resulted from the functional groups present in it.

\subsubsection{Scanning Electron Microscopy (SEM)}

The surface morphologies of both the raw and calcined CAE were viewed using SEM, and their images are shown in Figure 2. The SEM results indicated that the raw catalyst possessed large, irregular, and undefined particles, where the surfaces were assumed to be covered by adsorbed gases, volatile matter, and moisture. This explained why the raw catalyst exhibited a low level of activity. However, after calcination, the large and undefined particles present in the raw CAE broke down into smaller particles with a high surface area and large voids, as revealed in Figure $2 b$. This observation was due to the changes in composition of the catalyst components, as also revealed by the XRF and FTIR analyses. Most of the essential metallic compounds contained in the raw CAE catalyst were decomposed into their corresponding oxides and carbon dioxide, $\mathrm{CO}_{2}$, after the calcination process (Tan et al., 2015); this left cavities that indicated both the solid rearrangement and exit route of the eliminated components (Leofanti et al., 1997). This result aligns with the findings of Buasri et al. (2012), who reported that calcined carbonatederived catalysts are made up of particles with small shapes.

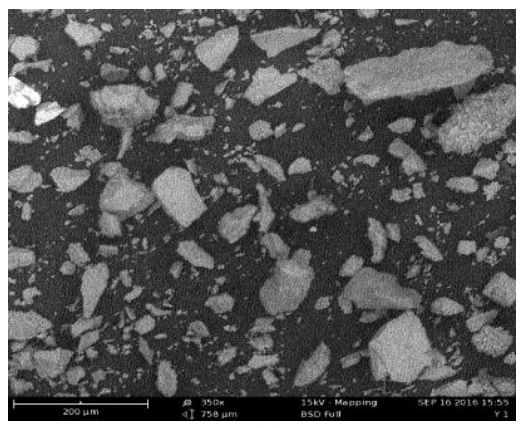

(a)

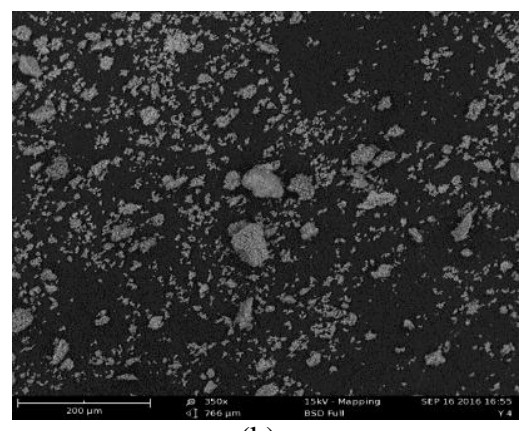

(b)

Figure 2 SEM images of (a) raw CAE; (b) calcined CAE catalysts

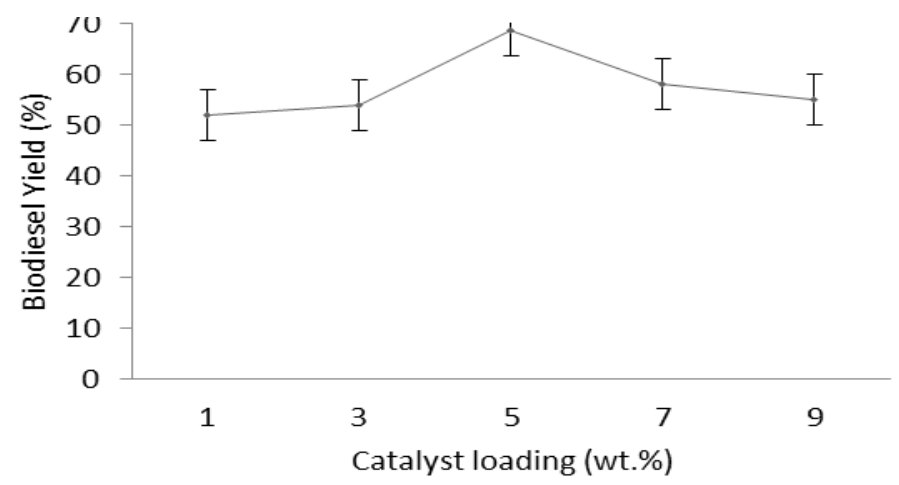

Figure 3 Effect of catalyst loading

\subsection{Effect of Different Process Variables on the Transesterification Reaction}

\subsubsection{Effect of the catalyst loading}

To study the effect of catalyst loading on biodiesel production, the transesterification reaction between WFO and methanol was conducted with different catalyst loadings varying from 1 wt $\%$ to $9 \mathrm{wt} \%$. An increase in biodiesel yield was recorded from $1 \mathrm{wt} \%$ to $5 \mathrm{wt} \%$, with the 
maximum close to $70 \%$, as can be seen in Figure 3. However, the yield did not increase when the catalyst loading was above $5 \mathrm{wt} \%$; this is because the reaction mixture becomes highly viscous at a higher loading of catalysts due to the formation of slurries, which results in mass transfer limitations and favors glycerol formation over biodiesel (Tan et al., 2015). Therefore, the optimum catalyst loading was found to be $5 \mathrm{wt} \%$, and this was used for further investigation.

\subsubsection{Effect of the reaction temperature}

The effect of the reaction temperature on the biodiesel yield is shown in Figure 4. The yield increased as the reaction temperature increased and gave the highest biodiesel yield of $70 \%$ at $60^{\circ} \mathrm{C}$. However, when the temperature reached the boiling point of methanol, a lot of methanol bubbles were formed, thereby inhibiting the mass transfer on the phase interface and resulting in a lower conversion, leading to less methanol in the medium. The drop in the biodiesel yield at temperatures exceeding the boiling point of methanol (around $65^{\circ} \mathrm{C}$ ) may have been due to the vaporization of methanol at these elevated temperatures, which reduced its amount in the reaction medium, thereby favoring the formation of glycerol over biodiesel (Olutoye \& Hameed, 2013). Nevertheless, the CAE catalyst exhibited better performance, mostly when compared with eggshell and crab shell, which provided biodiesel yields of $65 \%$ and $62 \%$, respectively (Shah et al., 2014).

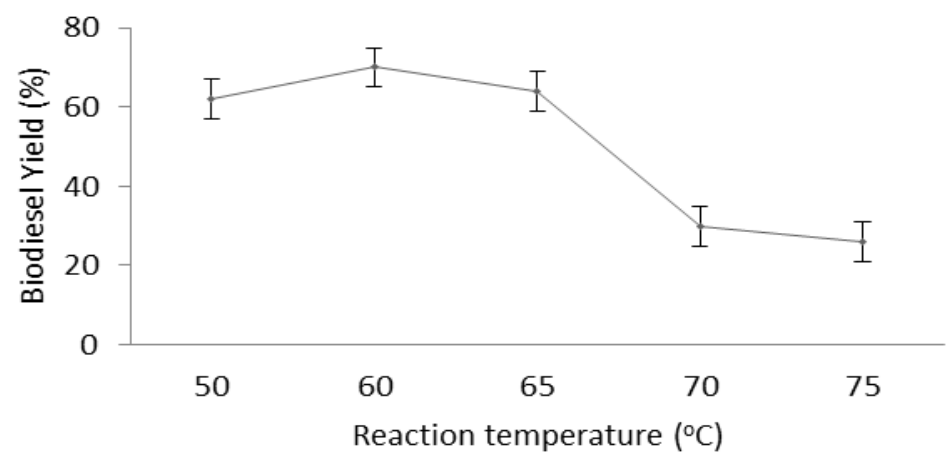

Figure 4 Effect of reaction temperature

\subsubsection{Effect of the reaction time}

The effect of increasing the reaction time during the transesterification reaction was also studied over the range of $1-3 \mathrm{~h}$, as can be seen in Figure 5.

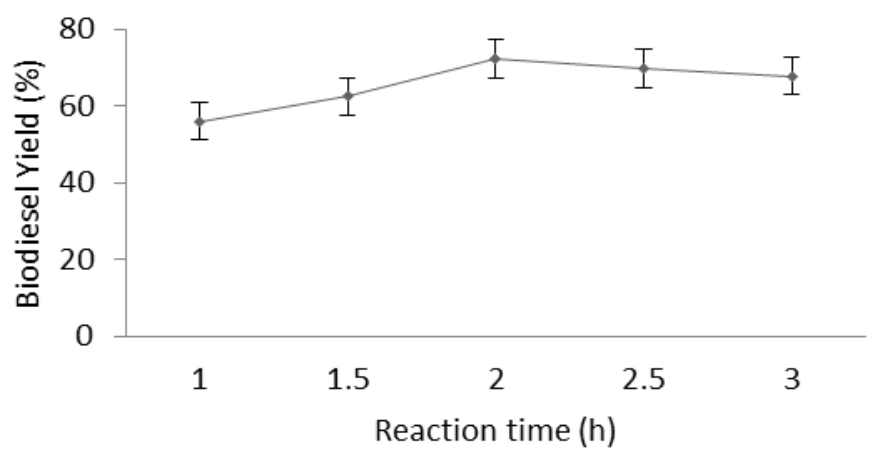

Figure 5 Effect of reaction time

The results showed that the yield increased with time, reaching the maximum yield at a reaction time of $2 \mathrm{~h}$. There was a slight decrease in the yield $1 \mathrm{~h}$ later, which was due to the evaporation that can occur during a prolonged reaction process. A difference of only $2.4 \%$ in the biodiesel yield was observed 30 min later. A similar observation was reported by Olutoye et al. (2015), 
who observed an extremely small difference in the amount of biodiesel between reaction times of 5 and $6 \mathrm{~h}$.

\subsection{Characterization of Biodiesel Yield Produced under Optimum Conditions}

\subsubsection{Physicochemical and fuel properties}

The biodiesel produced under optimum reaction conditions was characterized based on its physicochemical and fuel properties. Table 3 shows the properties of the WFO-derived biodiesel. These properties were compared with the ASTM/European (EN) standards for biodiesel. Some were found to be comparable and in reasonable agreement with the ASTM/EN standards. The flash point obtained for the biodiesel sample was higher, and it conformed to the ASTM/EN standard $\left(\geq 130^{\circ} \mathrm{C}\right)$. This implies that the produced biodiesel can be used for powering compression ignition or vehicular engines in hot weather (Oyerinde \& Bello, 2016). Meanwhile, the values of the cloud and pour points for the prepared biodiesel were found to be negative; this implies that the employed biodiesel feedstock has a lower degree of saturation and tendency to change to a semi-solid (Olutoye et al., 2015).

Table 3 Physicochemical and fuel properties of WFO-derived biodiesel compared with the ASTM standard

\begin{tabular}{lcc}
\hline \multicolumn{1}{c}{ Property } & WFO-based Biodiesel & $\begin{array}{c}\text { Biodiesel Standard } \\
\text { ASTM/EN }\end{array}$ \\
\hline Specific gravity & 0.883 & $0.86-0.90$ \\
Kinematic viscosity at $40^{\circ} \mathrm{C}\left(\mathrm{mm}^{2} / \mathrm{s}\right)$ & 3.76 & $1.9-6.0$ \\
Acid value $(\mathrm{mgKOH} / \mathrm{g})$ & 0.88 & $0.8 \mathrm{max}$ \\
Flash point $\left({ }^{\circ} \mathrm{C}\right)$ & 150 & $\geq 130^{\circ} \mathrm{C}$ \\
Cloud point $\left({ }^{\circ} \mathrm{C}\right)$ & -8 to -10 & - \\
Pour point $\left({ }^{\circ} \mathrm{C}\right)$ & -11 to -12 & - \\
\hline
\end{tabular}

\subsubsection{FTIR analysis}

The composition and functional groups of biodiesel prepared under optimum reaction conditions $\left(60^{\circ} \mathrm{C}\right.$ reaction temperature, $2 \mathrm{~h}$ reaction time, $5 \mathrm{wt} \%$ catalyst loading, and $6: 1$ methanol/WFO molar ratio) were confirmed by the FTIR spectrum (Figure 6).

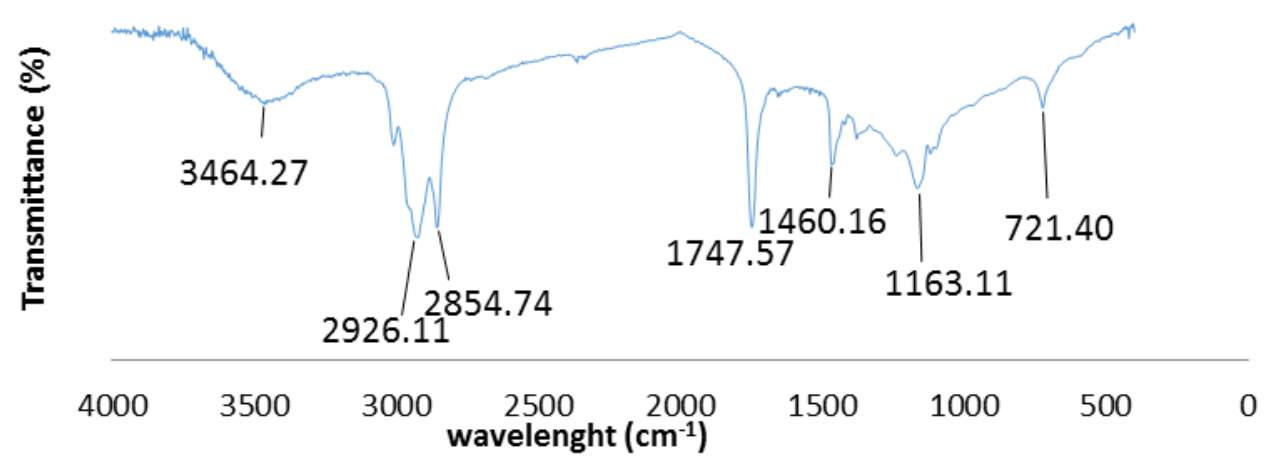

Figure 6 FTIR spectrum of biodiesel produced under optimum reaction condition

The broad absorption band at $3464.27 \mathrm{~cm}^{-1}$ in Figure 6 was attributed to $\mathrm{OH}$ stretching vibrations. Sharp bands at 2926.11 and $2854.74 \mathrm{~cm}^{-1}$ were due to the $\mathrm{C}-\mathrm{H}$ stretching vibrations of the methylene groups. The strong peaks at $1747.57 \mathrm{~cm}^{-1}(\mathrm{C}=\mathrm{O}$ ester $)$ and $1163.11 \mathrm{~cm}^{-1}(\mathrm{C}-\mathrm{O}$ ester), which were obviously present in the spectrum, were assigned to carbonyl functional groups; these two functional groups confirm the presence of esters and are only attributed to biodiesel. Similar observations were reported for biodiesel derived from peanut oil (Oyerinde \& Bello, 2016) and palm oil (Taufiq-Yap et al., 2011). Furthermore, the band at $1460.16 \mathrm{~cm}^{-1}$ 
could be attributed to the $\mathrm{CH}_{3}$ group in the methyl ester mixtures (Siatis et al., 2006), and the peak at $721.40 \mathrm{~cm}^{-1}$ was attributed to $\mathrm{C}-\mathrm{H}_{2}$ methylene rock. The presence of these functional groups confirmed the quality of the produced biodiesel, and this observation is in line with the experimental data reported by Yadav et al. (2010).

\section{CONCLUSION}

This study revealed that CAE eggshell is a good heterogeneous catalyst for the transesterification of WFO. The thermal treatment of the catalyst at $1,000^{\circ} \mathrm{C}$ for $4 \mathrm{~h}$ resulted in an increase in surface area, leading to better catalytic activity for the formation of methyl esters. Under the optimum conditions of a 6:1 molar ratio of methanol to oil, addition of $5 \mathrm{wt} \%$ of CAE catalyst, and $60^{\circ} \mathrm{C}$ reaction temperature, the biodiesel yield was $70 \%$ at $2 \mathrm{~h}$. This highly efficient and low-cost waste catalyst could make the process of biodiesel production from WFOs economically viable and fully ecofriendly, such that it would be competitive with petroleum diesel. The experimental results showed that the biodiesel produced in the present work has some fuel properties that are relatively close to those of mineral diesel and comparable to those of the ASTM biodiesel standards, while a few of its properties are not. Therefore, the catalyst may require modification with promoters, two-step transesterification due to the high free fatty acid content in WFO, and testing with various types of oils.

\section{REFERENCES}

Buasri, A., Chaikwan, T., Loryuenyong, V., Rodklum, C., Chaikwan, T., Kumphan, N., 2012. Continuous Process for Biodiesel Production in Packed Bed Reactor from Waste Frying Oil using Potassium Hydroxide Supported on Jatropha curcas Fruit Shell as Solid Catalyst. Applied Science, Volume 2, pp. 641-653

Chorkendorff, I., Niemantsverdriet, J.W., 2003. Concepts of Modern Catalysis and Kinetics: Weinhem. Germany: Wiley-VCH press

Di Serio, M., Dimiccoli, M., Cammarota, F., Nastasi, M., Santacesaria, E., 2005. Synthesis of Biodiesel via Homogeneous Lewis Acid Catalyst. Journal of Molecular Catalysis A: Chemical, Volume 239(1), pp. 111-115

Eletta, O.A.A., Ajayi, O.A., Ogunleye, O.O., Akpan, I.C., 2016. Adsorption of Cyanide from Aqueous Solution using Calcinated Eggshells: Equilibrium and Optimization Studies. Journal of Environmental Chemical Engineering, Volume 4, pp. 1367-1375

Henne, G.A., 2009. Anthill as a Resource for Ceramics. Published PhD thesis, Faculty of fine art, Kwame Nkrumah University of Science and Technology, Ghana

Lakhya, J.K., Singh, C., Jutika, B., Rupam, K., Dhanapati, D., 2012. Biochar Supported CaO as Heterogeneous Catalyst for Biodiesel Production. International Journal of Innovative Research \& Development, Volume 1(7), pp. 186-195

Leofanti, G., Tozzola, G., Padovan, M., Petrini, G., Bordiga, S., Zecchina, A., 1997. Catalyst Characterization: Characterization Techniques. Catalysis Today, Volume 34, pp. 307-327

Leung, D.Y.C., Wu, X., Leung, M.K.H., 2010. A Review on Biodiesel Production using Catalysed Transesterification. Applied Energy, Volume 87, pp. 1083-1095

Obadiah, A., Swaroopa, G.A., Kumar, S.V., Jeganathan, K.R., Ramasubbu, A., 2012. Biodiesel Production from Palm Oil using Calcined Waste Animal Bone as Catalyst. Bioresource Technology, Volume 116, pp. 512-516

Olutoye, M.A., Hameed, B.H., 2013. A Highly Active Clay-based Catalyst for the Synthesis of Fatty Acid Methyl Ester from Waste Cooking Palm Oil. Applied Catalysis A: General, Volume 450, pp. 57-62 
Olutoye, M.A., Wong, S.W., Chin, L.H., Asif, M., Hameed, B.H. 2016. Synthesis of Fatty Acid Methyl Esters via Transesterification of Waste Cooking Oil by Methanol with a Bariummodified Montmorillonite K10 catalyst. Renewable Energy, Volume 86, pp. 392-398

Oyerinde, A.Y., Bello, E.I., 2016. Use of Fourier Transformation Infrared (FTIR) Spectroscopy for Analysis of Functional Groups in Peanut Oil Biodiesel and its Blends. British Journal of Applied Science and Technology, Volume 13(3), pp. 1-14

Roschat, W., Kacha, M., Yoosuk, B., Sudyoaduk, T., Promarak, V., 2012. Biodiesel Production based on Heterogeneous Process Catalyzed by Solid Waste Coral Fragment. Fuel, Volume 2, pp. 194-202

Shah, B., Sulaimana, S., Jamal, P., Alam, M.Z., 2014. Production of Heterogeneous Catalysts for Biodiesel Synthesis. International Journal of Chemical and Environmental Engineering, Volume 5(2), pp. 73-75

Sharma, Y.C., Singh, B., Korstad, J., 2010. Application of an Efficient Nonconventional Heterogeneous Catalyst for Biodiesel Synthesis from Pongamia pinnata oil. Energy Fuels, Volume 24, pp. 3223-3231

Siatis, N.G., Kimbaris, A.C., Pappas, C.S., Tarantitlis, P.A., Polissiou, M.G., 2006. Improvement of Biodiesel Production based on the Application of Ultrasound: Monitoring of the Procedure by FTIR Spectroscopy. Journal of the American Oil Chemists' Society. Volume 83(1), pp. 1-7

Tan, Y.H., Abdullah, M.O., Hipolito, C.N., Taufiq-Yap., Y.H., 2015. Waste Ostrich and Chicken-Eggshells as Heterogeneous Base Catalyst for Biodiesel Production from Used Cooking Oil: Catalyst Characterization and Biodiesel Yield Performance. Applied Energy, Volume 2, pp. 1-13

Taufiq-Yap, Y.H., Abdullah, N.F., Basri, M., 2011. Biodiesel Production via Transesterification of Palm Oil using $\mathrm{NaOH} / \mathrm{Al}_{2} \mathrm{O}_{3}$ Catalysts. Sains Malaysiana, Volume 40(6), pp. 587-594

Tsai, W.T., Yang, J.M., Lai, C.W., Cheng, Y.H., Lin, C.C., Yeh, C.W., 2006. Characterization and Adsorption Properties of Eggshells and Eggshell Membrane. Bioresource Technology, Volume 121, pp. 167-173

Wei, Z., Xu, C., Li, B., 2009. Application of Waste Eggshell as Low-cost Solid Catalyst for Biodiesel Production. Bioresource Technology, Volume 100, pp. 2883-2885

Yadav, P.K.S., Singh, O., Singh, R.P., 2010. Performance Test of Palm Fatty Acid Biodiesel on Ccompression Ignition Engine. Journal of Petroleum Technology and Alternative Fuels, Volume 1(1), pp. 1-9 